\title{
MINIATURIZATION OF A PLANAR STRIP-SHAPED MONOPOLE ANTENNA FOR WLAN APPLICATION
}

\author{
YASSER A. FADHEL ${ }^{*}$, MUSA ATAŞ ${ }^{* *}$, AND REVINK M. ABDULHAKIM ${ }^{* * *}$ \\ ${ }^{*}$ Dept .of Electrical and Computer Engineering, University of Duhok,Kurdistan Region-Iraq \\ ** Dept. of Computer Engineering, Siirt University. \\ *** Dept. of Computer and Communication Engineering, University of Nawroz,Kurdistan Region-Iraq
}

\begin{abstract}
Recently the demand for compact size devices has been increased whether being used for sensor networks, smart phones, smart watches or RFID tags etc. One of the most important parts of these systems is its antenna which facing a big challenge of having a low profile that meets the required size of these wireless communication devices. This paper presents a design of a simple planar strip monopole antenna for WLAN application. Miniaturization has been performed on this antenna via two different techniques. Firstly corrugations were added to both side edges of the radiating strip that reduced the size with $10.7 \%$ of the original size. Secondly the radiating strip has been meandered to increase the size reduction to about $14.28 \%$. Both simulation and measured results shown that meandering technique was more efficient in miniaturizing the size of the designed antenna due to forcing the current to follow a meandered path that rise up with shorter height.
\end{abstract}

KEYWORDS: Miniaturized Antennas, Strip-Shaped Antenna, Meandering, Corrugation.

\section{INTRODUCTION}

$\mathbf{L}^{\mathrm{a}}$ ast years witnessed a very large integration of wireless devices in somehow to be very compact and small in size while working on multiple bands of frequencies, and as much as development advanced in wireless devices these systems require microwave components that have high performance and smaller size.

One of the big challenges for such small size devices is the compacting of their antennas which is difficult because it needs for maintaining antenna edges or aspects effectively equal to some wavelengths which are opposite to the required resonating frequencies used by those wireless communication devices.

Microstrip antennas are vastly used in satellite, aviation, military and various commercial applications, due to their suitable size, price, having a good performance and easy for installation. Accordingly microstrip antennas are more nominated to serve as miniaturized antennas and many attempts are devoted for reducing microstrip antennas in size such as using Defected Microstrip Structure (DMS), Defected Ground Structure (DGS), a dielectric substrate of high permittivity at the ground plane or a combination of them $[1,2]$. Many of the communication systems need for antennas to be working at multiband antennas and this has been achieved via different methods like notch technique, slot, 
metamaterial and fractal method [3, 4]. Some researchers replaced the traditional substrate by a $\mu$-negative metamaterials (MNG) which miniaturize the size of a rectangular patch antenna to $77 \%$ [5]

Meandering the microstrip feed line has been used in a previous work to perform impedance matching over a very wide band range of frequencies. This technique was suggested for fixing UWB antennas being designed according to certain formulas $[6,7]$. In other work the edges of the radiator and ground plane of a planar Tapered Slot Antenna (TSA) have been corrugated to miniaturize its overall size while maintaining its features unchanged [8].

A square-shaped monopole antenna has been designed by [9] to be operated at a frequency band of $300 \mathrm{MHz}-3000 \mathrm{MHz}$. Then it has been developed by corrugating its radiating element of square-shape laterally. Although the width of the radiating element has been reduced by about $60 \%$ but its height was unchanged, therefore no reduction was performed in the height and also after performing this

$$
f_{L}=\frac{c}{\lambda}=\frac{7.2}{(L+r+P) * k} G H z
$$

Where the values of $r$ and $L$ are the radius and height of a virtual cylindrical monopole antenna, respectively. This virtual antenna considered as an equivalent for the strip-shaped planar monopole antenna. And according to this method suggested in [10], they could be calculated as follow:

$$
\begin{array}{ll}
=L_{\text {rad }} & L \\
= & W_{T}
\end{array}
$$

corrugation on the antenna it didn't remain planar anymore. Whereas in this paper the corrugation and meandering will be used to miniaturize the overall size of a simple strip-shaped monopole antenna while keeping the planarity and other features of the parent strip-shaped antenna unchanged. After the design of antennas, simulation has been performed by CST Microwave Studio 2014. Then practical implementation on FR4 PCB boards has been performed and some experimental measurements have been taken via Rohde \& Schwarz ${ }^{\circledR}$ ZVL13 Vector Network Analyzer which validates the simulation results.

\section{ANTENNA DESIGN}

A planner strip shape antenna has been designed as a simple planar monopole antenna to be working on $2.45 \mathrm{GHz}$ for serving in WLAN devices. The planner strip shape antenna is an extension from the microstrip feed line as shown in Fig. (1). The size of antenna has been designed according to [10] as follows:
Where $L_{\mathrm{rad}}$ is the length of the strip-shaped radiator, $W_{\mathrm{T}}$ is the width of the microstrip feed line, $P$ is the length of the $50 \Omega$ feed line in $\mathrm{cm}$ between the ground plane and the radiator, but in this design the radiator considered as an extension to the microstrip feed line by having the same width, therefore $P$ will be omitted or included in the $L_{\mathrm{rad}}$ dimension, and $k=\sqrt{\varepsilon_{\text {eff }}}$. The approximated value of $\varepsilon_{\text {eff }}$ is given by [11]: 


$$
\approx \frac{\varepsilon_{r}+1}{2} \quad \varepsilon_{\text {eff }}
$$

If FR4 substrate having a thickness of 1.6 $\mathrm{mm}$ is used, then equation (4) gives $\varepsilon_{\text {eff }}=2.65$, and accordingly $k$ will be 1.627 . This value is suggested by [12] to be taken 1.15 as empirical value. Therefore if the lower frequency is chosen to be $2.45 \mathrm{GHz}$, then $L_{\mathrm{rad}}=25.4 \mathrm{~mm}$ but will be taken $(25.5 \mathrm{~mm})$.

The ground plane length has been taken as a

$$
Z_{o}=\frac{87}{\sqrt{\varepsilon_{r}+1.41}} \ln \left(\frac{5.98 h}{0.8 W_{S t r L}+t}\right)
$$

Where $Z_{o}$ is the characteristic impedance of the microstrip feed line, $h$ is the thickness of substrate which has been taken $1.6 \mathrm{~mm}$ as a typical value, $t$ is the metallization thickness which is taken as $0.035 \mathrm{~mm}, W_{\text {StrL }}$ is the microstrip feed line width, and $\varepsilon_{r}$ for FR4

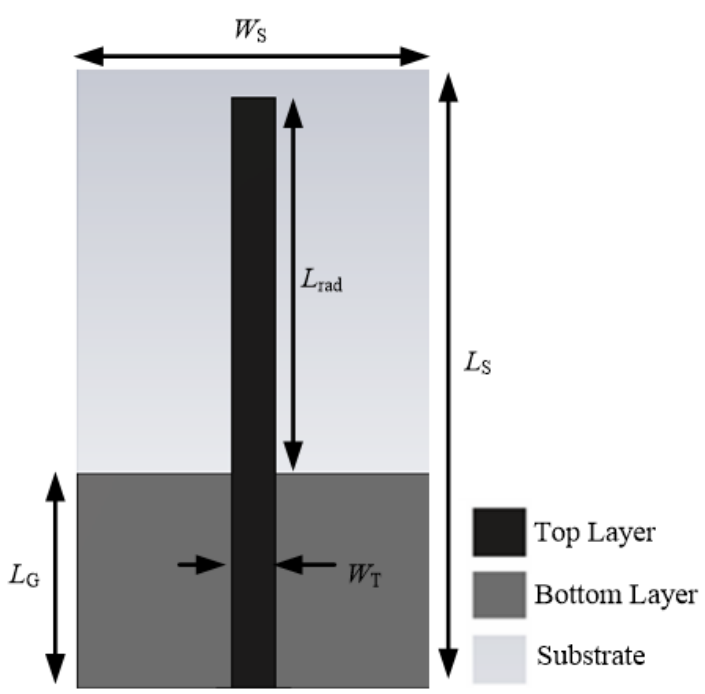

(a) substrate is 4.3. Therefore, for a characteristic impedance of $50 \Omega, W_{S t r L}$ must be equal to 3 $\mathrm{mm}$, and for simplicity $W_{\text {StrL }}$ has been named $W_{t}$ in Fig.1. The aforementioned design parameters and others are shown in the Table 1.

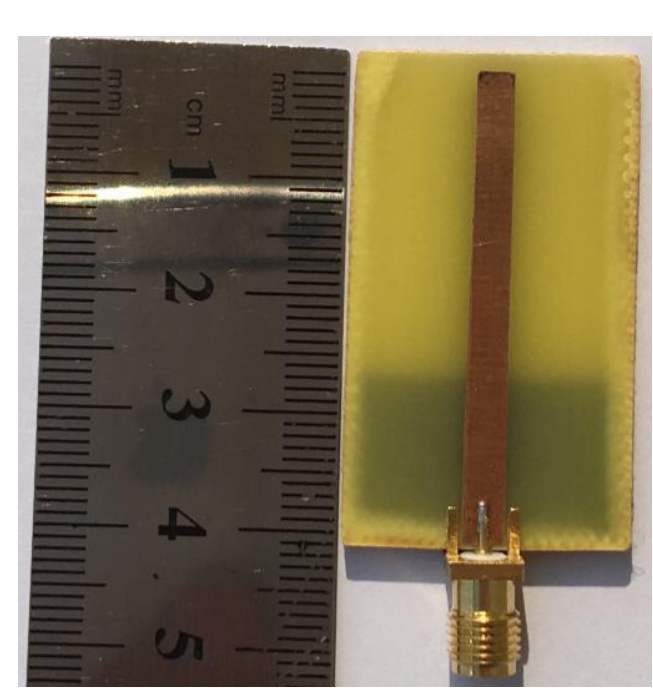

(b)

Fig.(1):- Geometry of the strip-shaped monopole antenna (a) Simulated, and (b) Fabricated. 
Table (1 ):-Design parameter of strip-shaped monopole antenna.

\begin{tabular}{cc}
\hline Parameter & Dimension (mm) \\
\hline$L_{\mathrm{rad}}$ & 25.5 \\
\hline$L_{S}$ & 42 \\
\hline$L_{G}$ & 14.5 \\
\hline$W_{S}$ & 24 \\
\hline$W_{T}$ & 2.8 \\
\hline
\end{tabular}

\section{MINIATURIZATION}

After designing the strip-shaped planar antenna, it is required to miniaturize it while maintaining its characteristics. The miniaturization has been performed via two different ways. Firstly, it has been done by corrugating the edges of the strip-shape radiator in somehow to get repeated slots on edges. These slots have been optimized by simulation to get optimum depth $\left(W_{\text {Slot }}\right)$ and length $\left(L_{\text {Slot }}\right)$ as shown in Table 2. This technique has reduced the actual physical height of the radiator but the required electrical path in front of the current has been almost kept unchanged, because the current flowing through the radiator will mainly distributed at edges and it will follow a corrugated path in its flow to get the required path length just like the original strip-shaped antenna. Accordingly, the required features of the antenna have been maintained while the overall size is reduced to $89.3 \%$ $(37.5 * 24 / 42 * 24=0.8928)$ of the original antenna.

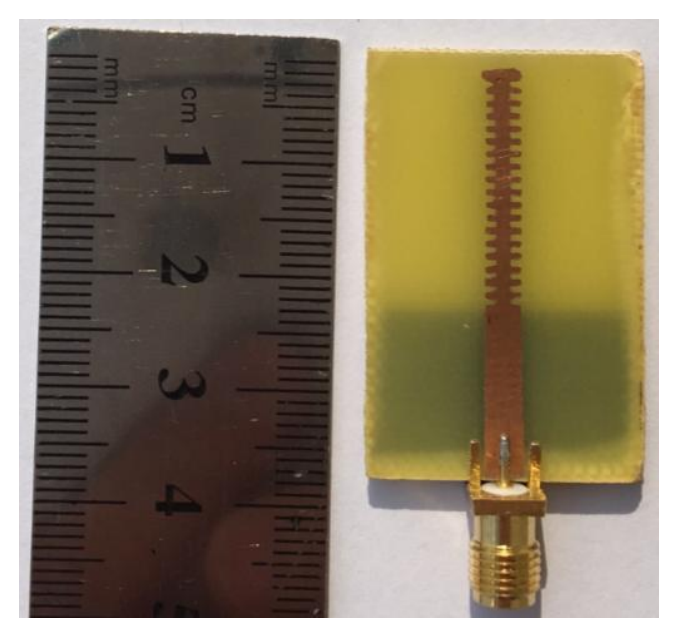

(b)

Fig. (2):- Geometry of the corrugated strip-shaped monopole antenna (a) Simulated, and (b) Fabricated. 
Table (2):- Design parameter of corrugated strip-shaped monopole antenna.

\begin{tabular}{cc}
\hline Parameter & Dimension (mm) \\
\hline$L_{\text {rad }}$ & 21 \\
\hline$L_{\text {Slot }}$ & 0.75 \\
\hline$L_{S}$ & 37.5 \\
\hline$L_{G}$ & 14.5 \\
\hline$W_{S}$ & 24 \\
\hline$W_{\text {Slot }}$ & 1 \\
\hline$W_{T}$ & 2.8 \\
\hline
\end{tabular}

The second technique was achieved through

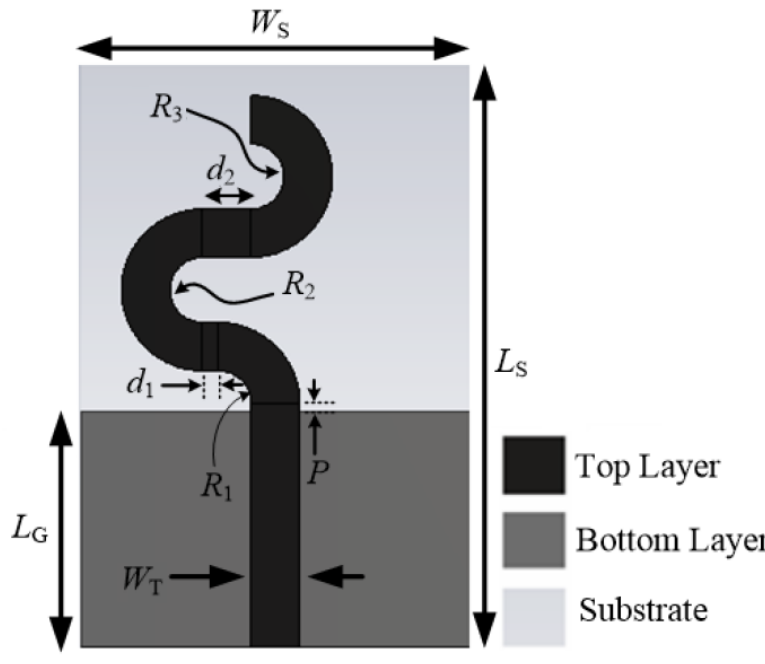

(a) meandering the strip-shaped radiator to reduce the overall height of the radiator while maintaining the required actual path against the current. Therefore physically the overall height has been reduced while the required electrical length has been maintained to keep resonating at the same frequency as that of the original antenna. The meandered strip-shaped antenna is shown in Fig.3 and all of its parameters are listed in Table 3. The dimensions of this antenna have been optimized to get closer features to the parent antenna, and the overall size is reduced to $85.7 \%(36 * 24 / 42 * 24=0.857)$ of the original antenna.

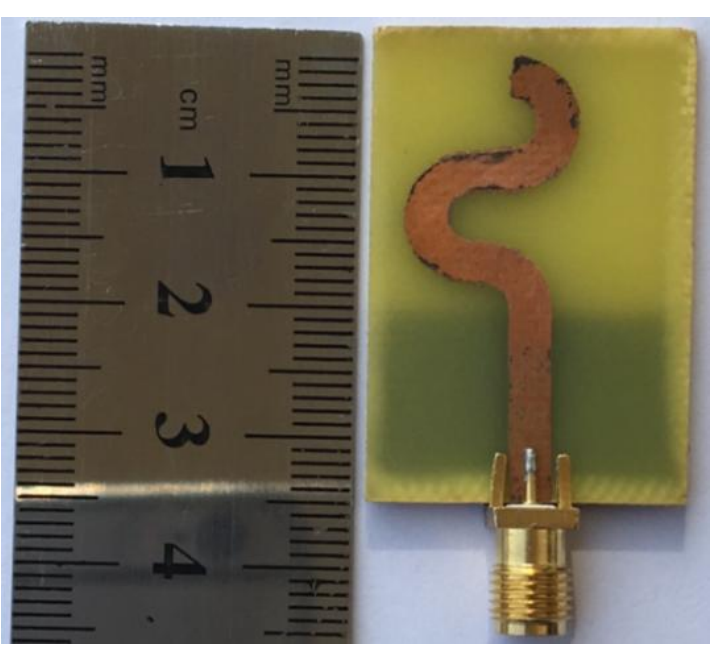

(b)

Fig. (3):- Geometry of the meandered strip-shaped monopole antenna (a) Simulated, and (b) Fabricated. 
Table (3):- Design parameter of corrugated strip-shaped monopole antenna.

\begin{tabular}{cc}
\hline Parameter & Dimension (mm) \\
\hline$d_{1}$ & 1 \\
\hline$d_{2}$ & 3 \\
\hline$R_{1}$ & 2 \\
\hline$R_{2}$ & 2 \\
\hline$R_{3}$ & 2 \\
\hline$L_{S}$ & 36 \\
\hline$L_{G}$ & 14.5 \\
\hline$P$ & 0.5 \\
\hline$W_{S}$ & 24 \\
\hline$W_{\mathrm{T}}$ & 2.8 \\
\hline
\end{tabular}

antennas have been simulated. Fig.4 shows the simulated return loss for the strip-shaped monopole antenna, corrugated strip-shaped monopole antenna, and meandered strip-shaped monopole antenna. It shows that all of these antennas are maintaining their working on the $2.45 \mathrm{GHz}$ band for WLAN while the meandered strip-shaped antenna advanced in getting another resonant band suitable for $5.5 \mathrm{GHz}$ as well. Investigating the surface current distributions Fig.s5 to Fig.7 for the three designed antennas, it has been concluded that the current is mostly concentrated at the edges of the radiators. Therefore in corrugated strip-shaped antenna the current will follow the corrugated path of the radiator edge and it will cross the required path with less height compared to the straight strip-shaped antenna, which validates this technique of miniaturization. The same thing happened in the meandered strip-shaped antenna as well, but this time it has been done by meandering the whole strip-shaped radiator to get more reduction in the overall height and more forcing of the current to follow a meandrous or zigzag way. Fortunately, this technique has gained another resonating at higher frequency band of WLAN around $5.5 \mathrm{GHz}$, thus became a dual-band WLAN planar antenna instead of single-band.

After completion of the design and simulation of aforementioned antennas, all three antennas have been fabricated as shown in the section (b) of Fig.s1 3, and tested via Rohde \& Schwarz ${ }^{\circledR}$ ZVL13 Vector Network Analyzer. The return loss data has been measured for all three antennas and plotted as comparison with their simulation one as shown in Fig.s8 10. The measured data almost agree with the simulated one except some deviations due to imperfection of fabrication, especially that of shifting of the lower resonating dip. Nevertheless, the practical measurements validate the design and the modification done to miniaturize the size of the strip-shaped antenna. Therefore the miniaturized antennas will be working with almost same features with least size and this was the goal of this research.

The simulated and measured radiation patterns in $\mathrm{E}$ and $\mathrm{H}$ planes for the three antennas are shown in Fig.s 11 13. Measured 
radiation patterns are almost meet simulation patterns. And aso show that the radiation pattern has not been affected by the miniaturization that performed by corrugation nor meandering. The radiation pattern for the meandered strip-shaped monopole antenna is plotted at $5.5 \mathrm{GHz}$ in addition to $2.45 \mathrm{GHz}$ because it works on dual-bands of WLAN. Finally, the simulated realized gain of strip-shaped antenna has been calculated to be $(2.052 \mathrm{~dB})$ at $2.45 \mathrm{GHz}$ and $(1.823 \mathrm{~dB})$ at 2.45 $\mathrm{GHz}$ for the corrugated strip-shaped antenna which are a moderate values, while for the meandered strip-shaped antenna it was found to be $(10.17 \mathrm{~dB})$ at $2.45 \mathrm{GHz}$ and $(12.08 \mathrm{~dB})$ at $5.5 \mathrm{GHz}$.

\section{CONCLUSIONS}

Two techniques have been introduced to miniaturize a simple strip-shape monopole antenna. Firstly, by corrugating the edges of the strip-shaped radiator. Secondly, by meandering the radiator. It has been shown that both techniques were succeeded in miniaturizing the overall size. In corrugation method the size has been reduced to $89.3 \%$ of the original parent antenna (i.e. the strip-shaped antenna), while in meandering method the size has been reduced to $85.7 \%$ of the parent antenna. Results shown that meandering technique was more efficient due to the reduction in size was done by $14.28 \%$ which is more than $10.7 \%$ for the other technique. Another advantage found by getting a dual-band resonating by meandering which enables working on dual-band of WLAN. Radiation patterns hasn't affected by the radiator shape modifications performed by both techniques. The measured data have also validated the simulated results.

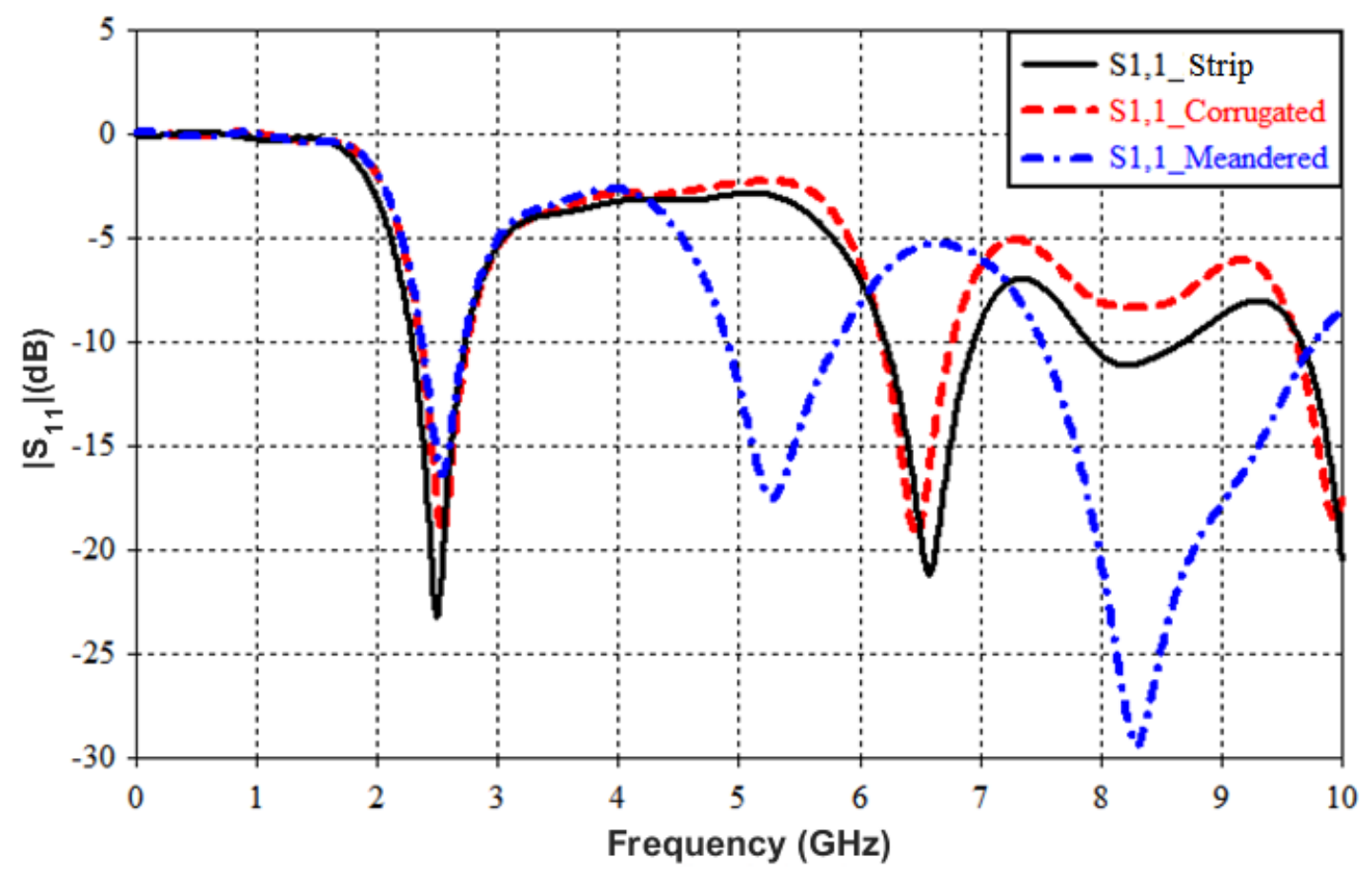


Fig.(4):- Comparison of simulated return loss curves for the strip-shaped monopole antenna, corrugated strip-shaped monopole antenna, and meandered strip-shaped monopole antenna.

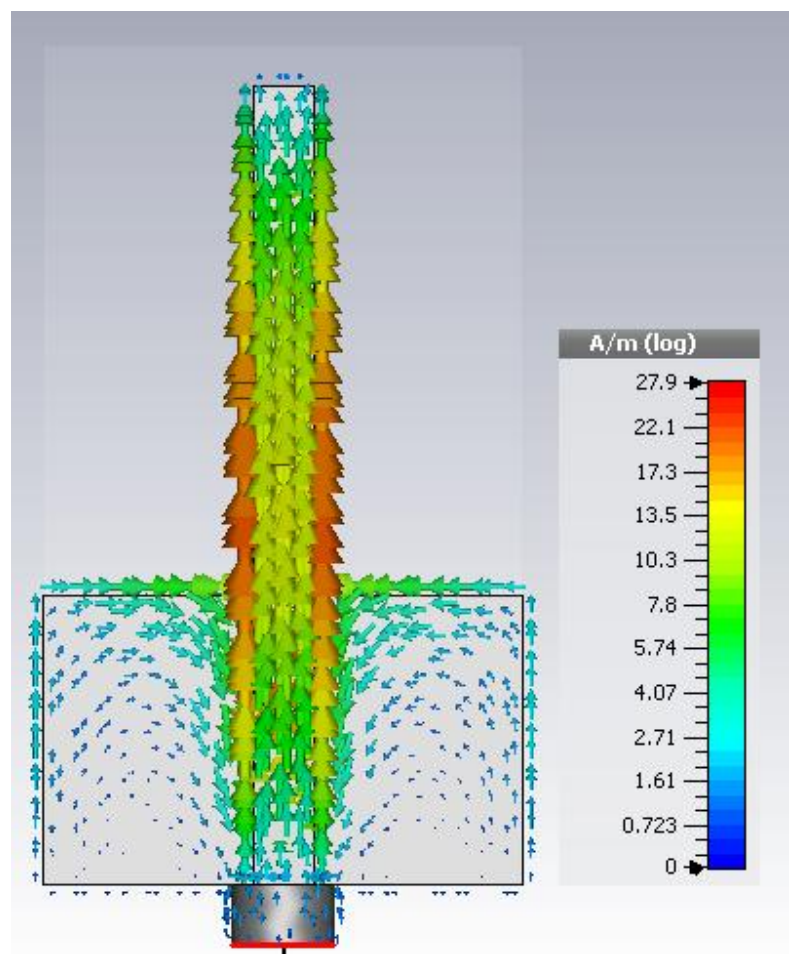

Fig.(5):- Surface current distribution for strip-shaped monopole antenna at $2.45 \mathrm{GHz}$.

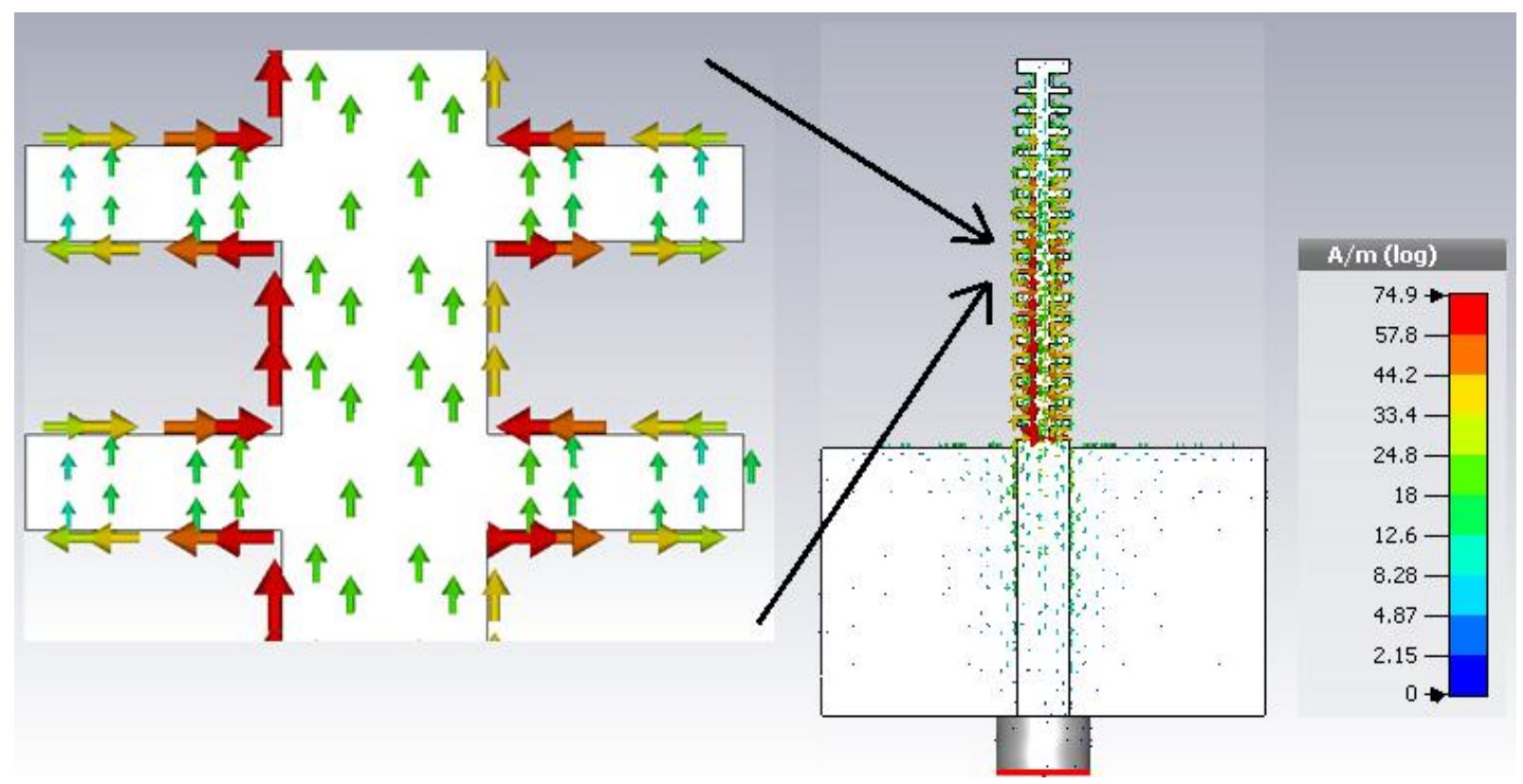


Fig.(6):- Surface current distribution for the corrugated strip-shaped monopole antenna at $2.45 \mathrm{GHz}$.

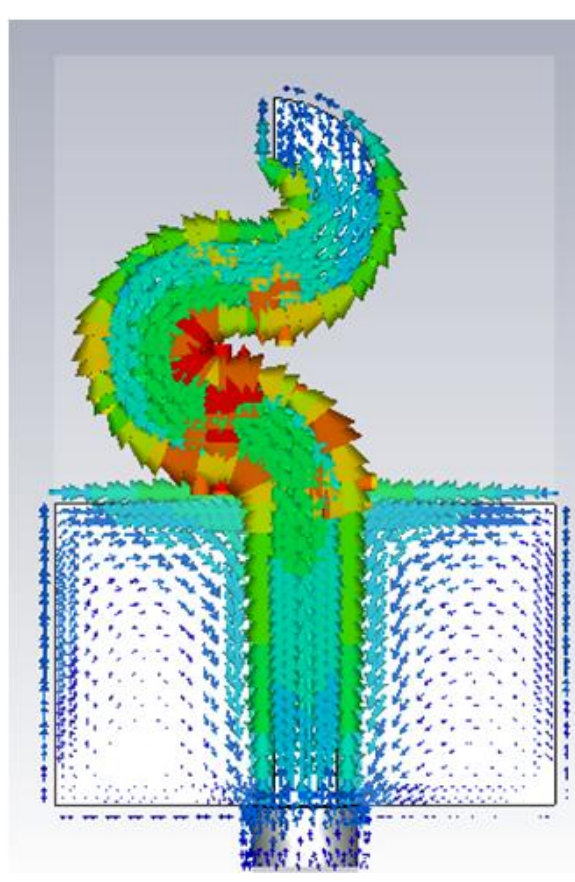

(a)
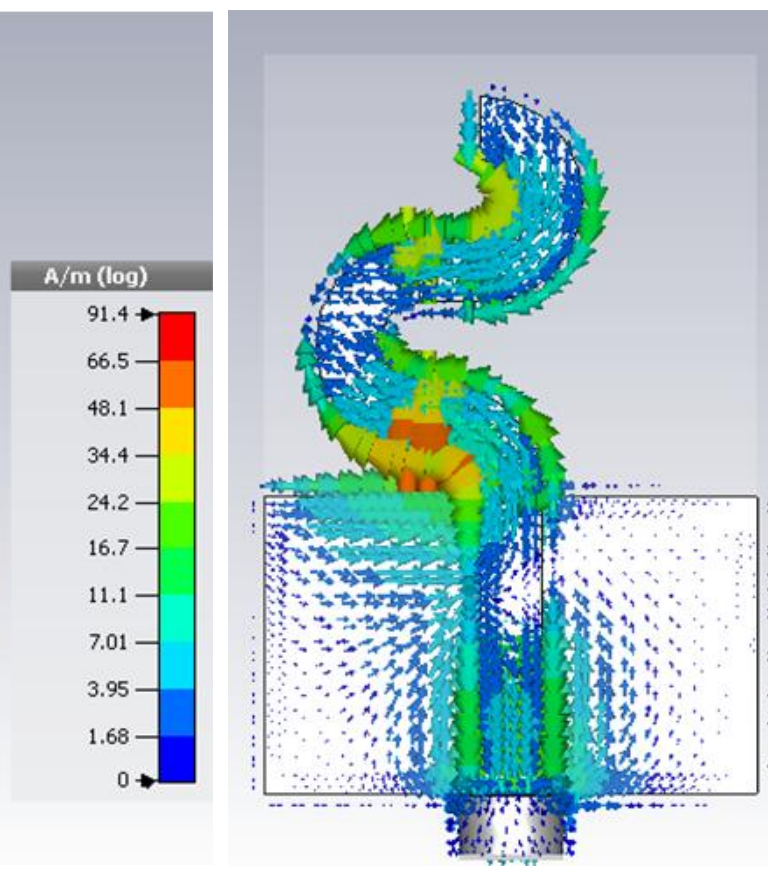

(b)

Fig.(7):- Surface current distribution for he meandered strip-shaped monopole antenna at (a) $2.45 \mathrm{GHz}$, and (b) $5.5 \mathrm{GHz}$. 


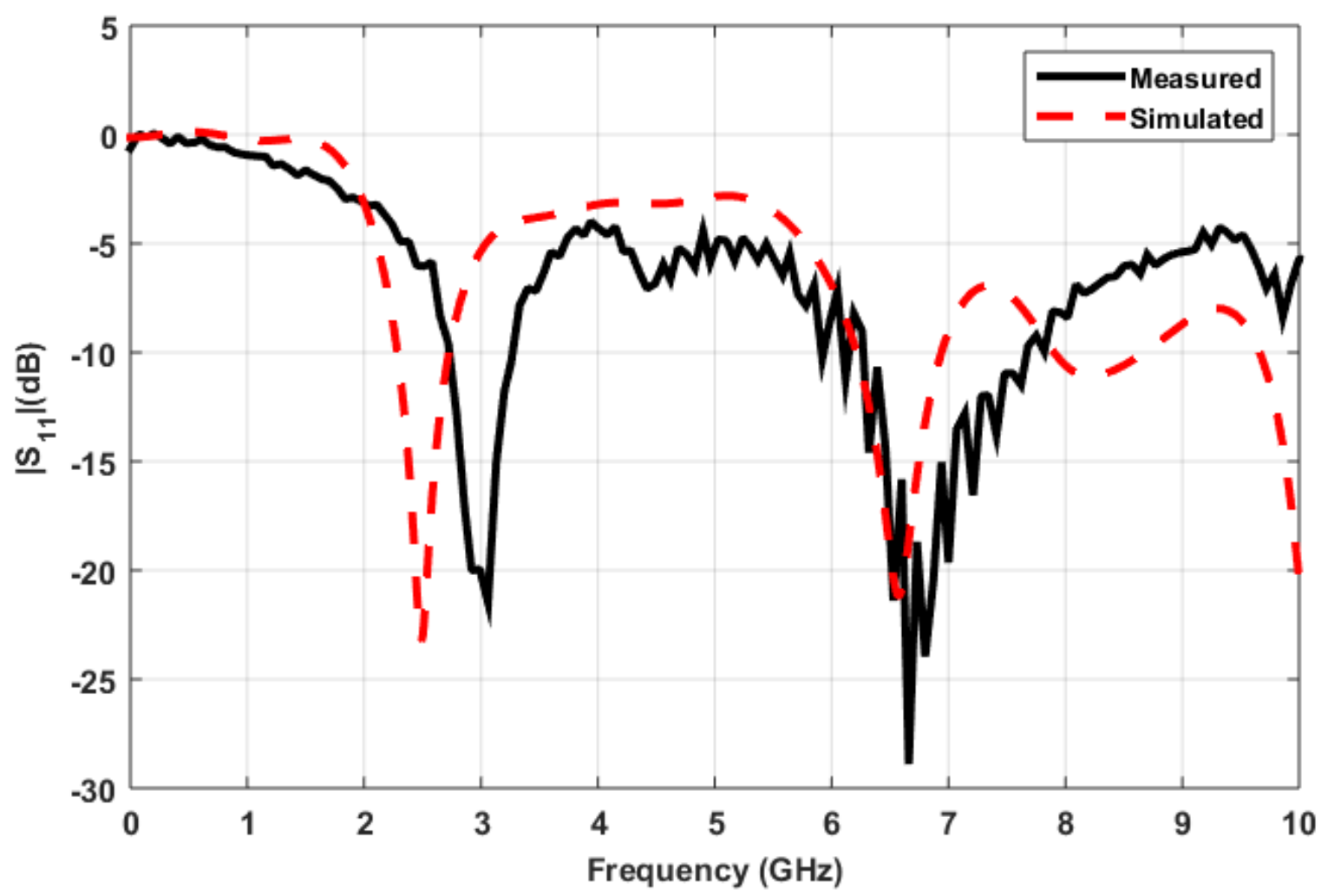

Fig(.8):- Measured and simulated return loss curves for the strip-shaped monopole antenna

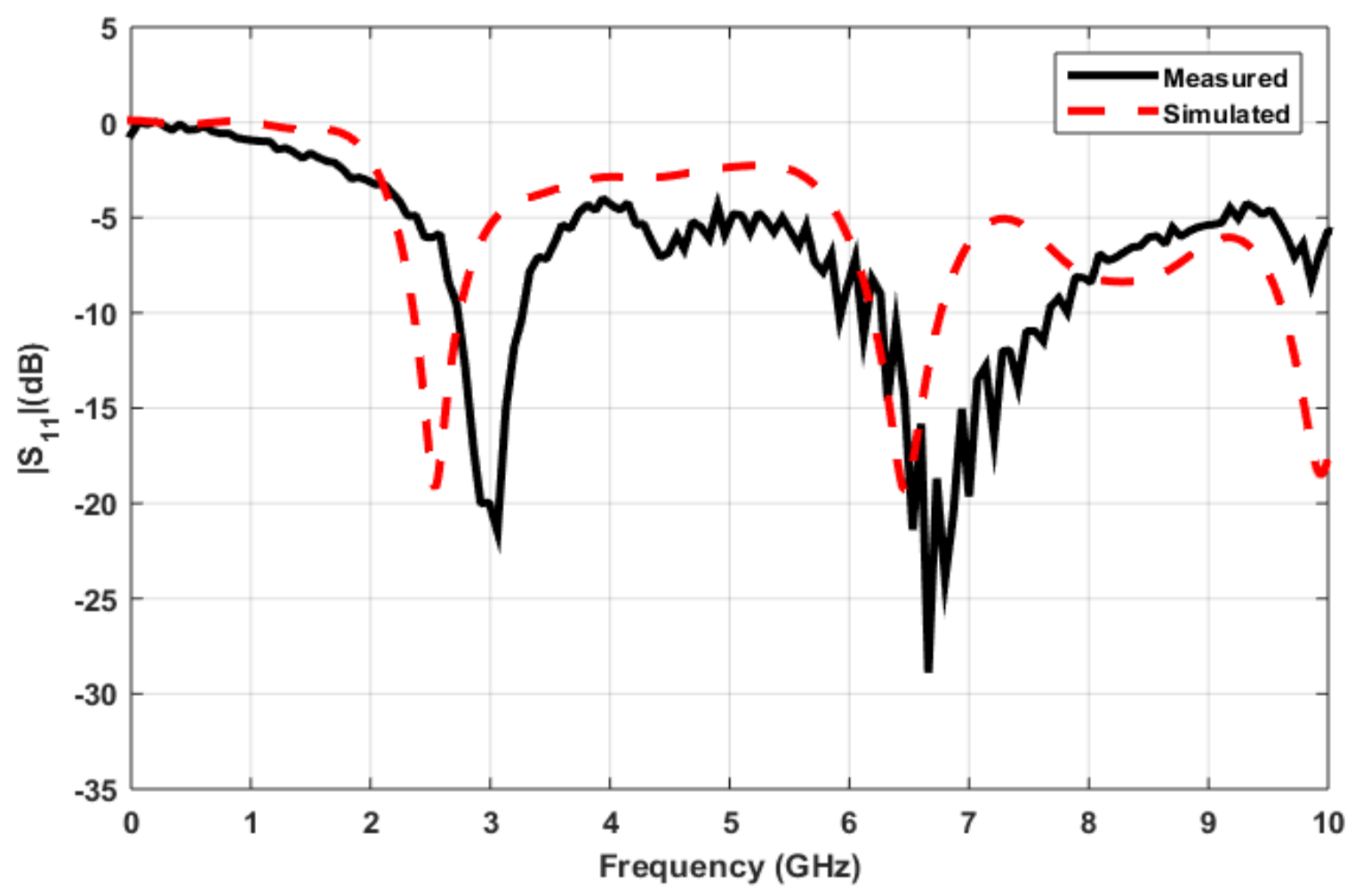


Fig(.9):- Measured and simulated return loss curves for the corrugated strip-shaped monopole antenna

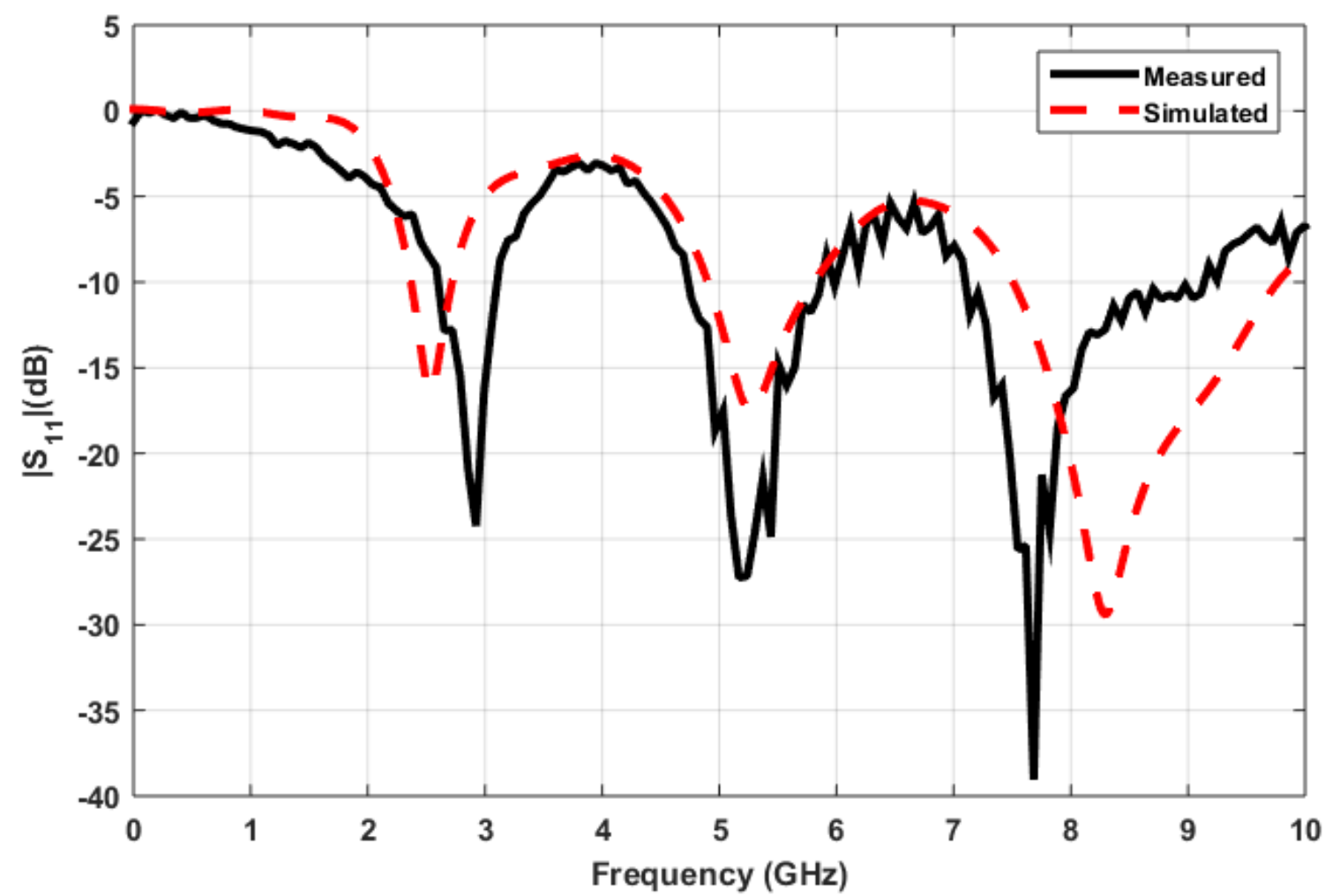

Fig.(10) :-Measured and simulated return loss curves for the meandered strip-shaped monopole antenna
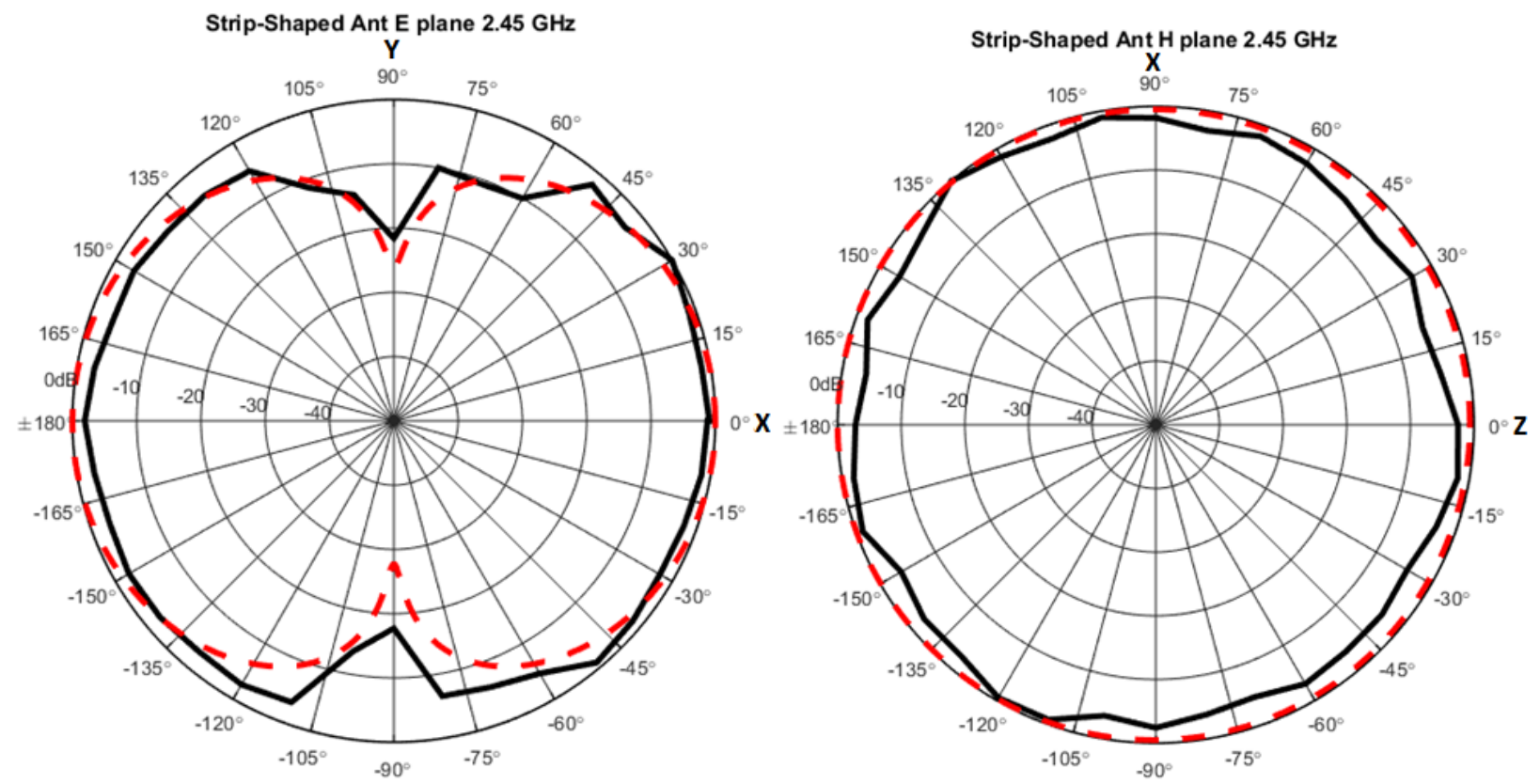

Fig.(11):- Measured (-) and simulated (- - -) radiation patterns of the strip-shaped monopole antenna in E and H 
planes, at frequency of $2.45 \mathrm{GHz}$.
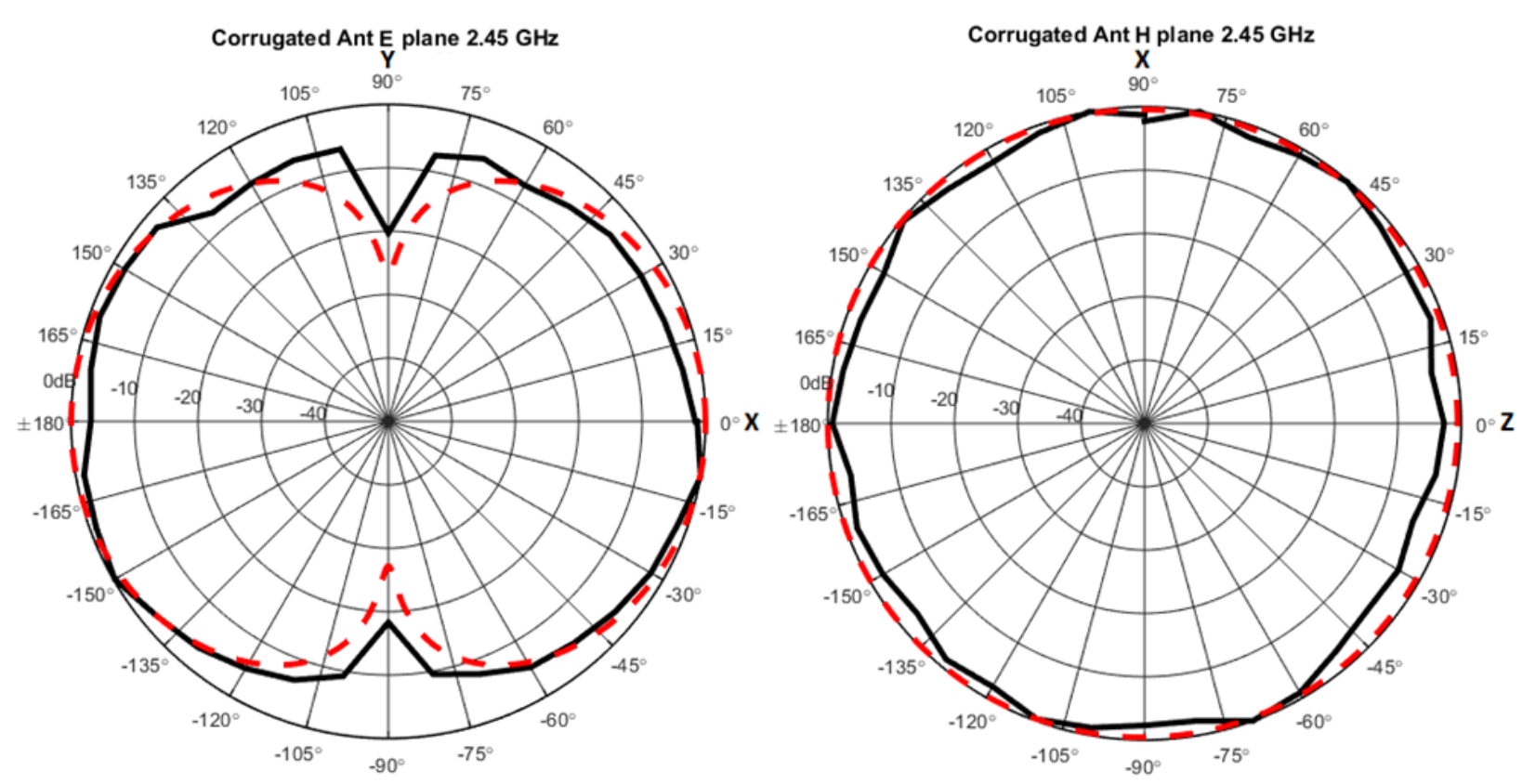

Fig.(12):- Measured (-) and simulated (- - -) radiation patterns of the corrugated strip-shaped monopole antenna in E and $\mathrm{H}$ planes, at frequency of $2.45 \mathrm{GHz}$.
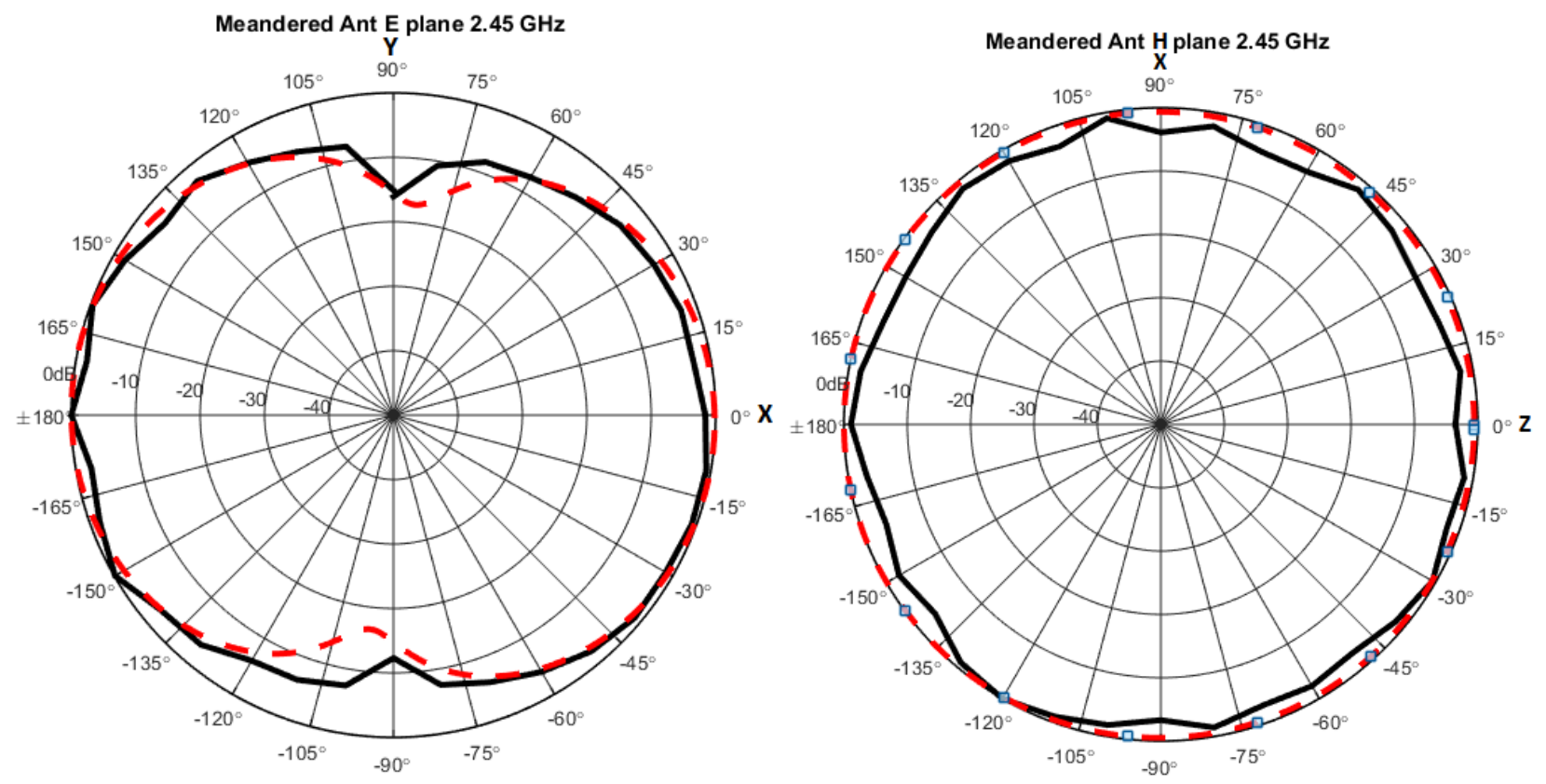

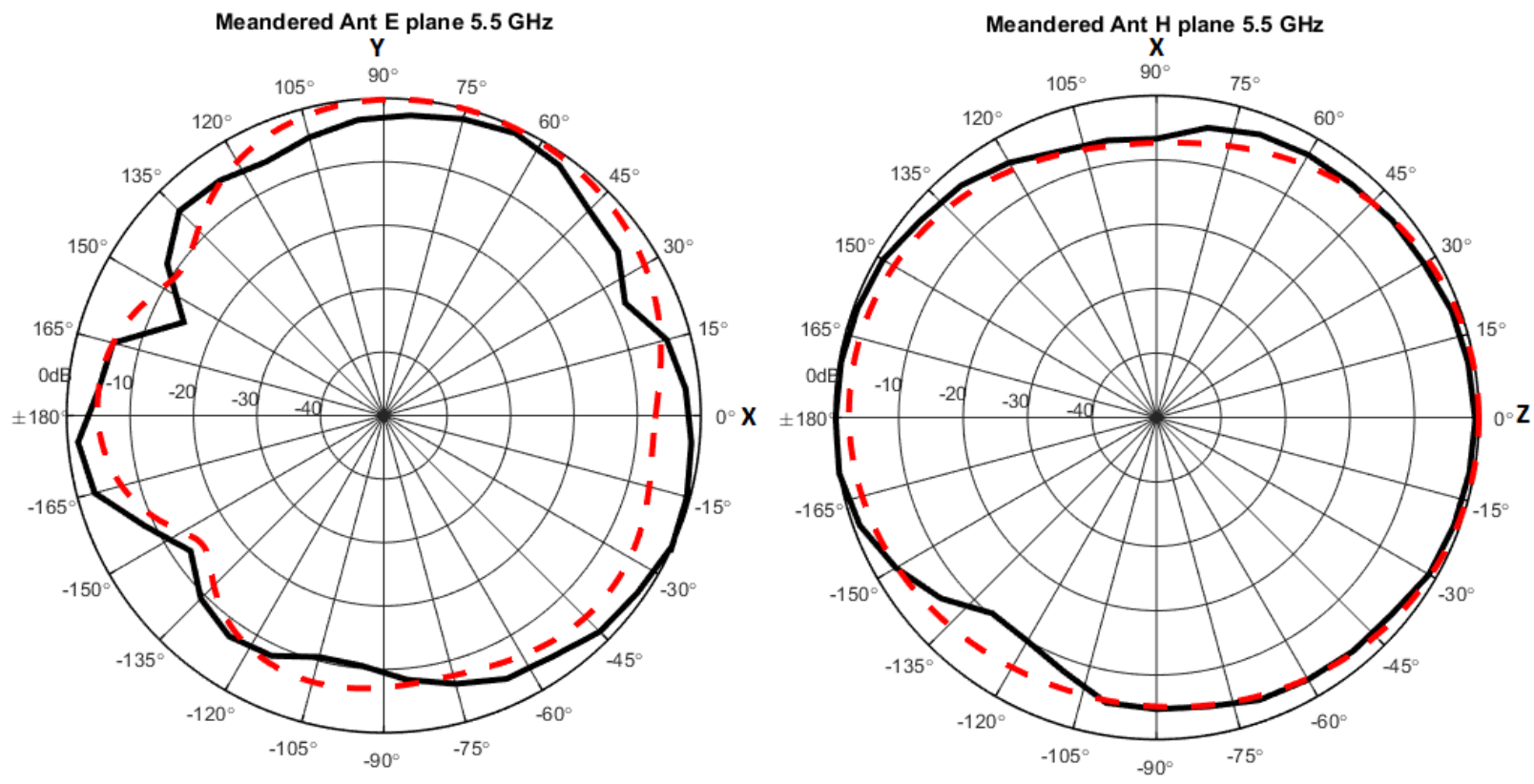

Fig.(13):- Measured (-) and simulated (- - -) radiation patterns of the meandered strip-shaped monopole antenna in E and $\mathrm{H}$ planes, at the two frequencies 2.45 and $5.5 \mathrm{GHz}$.

\section{REFERENCES}

[1] Chakraborty, M., Rana, B., Sarkar, P., and Das, A. (2012), Size reduction of microstrip antenna with slots and defected ground structure. International Journal of Electronics Engineering, Vol. 4, No. 1, 61-64.

[2] Elftouh, H., Touhami, N. A., and Aghoutane, M. (2015), Miniaturized microstrip patch antenna with spiral defected microstrip structure. Progress In Electromagnetics Research Letters, 53, 37-44.

[3] Alam, M. S., Islam, M. T., and Misran, N. (2012), A novel compact split ring slotted electromagnetic bandgap structure for microstrip patch antenna performance enhancement. Progress In Electromagnetics Research, 130, 389-409.

[4] Sayem, A. T. M., and Ali, M. (2006), Characteristics of a microstrip-fed miniature printed Hilbert slot antenna. Progress In Electromagnetics Research,
$56,1-18$.

[5] Bazrkar, A., Gudarzi, A. and Mahzoon, M. (2012), Miniaturization of Rectangular Patch Antennas Partially Loaded With $\mu$-Negative Metamaterials. International Conference on Electronics, Biomedical Engineering and its Applications (ICEBEA'2012). Dubai, 7-8 January.

[6] Fadhel, Y. A., and Sayidmarie, K. H. (2011), A Novel UWB Impedance Matching for Planar Circular Monopole Antenna Via Meandering the Microstrip Feed Line. Proceedings of ISAP2012 (pp. 539-542), Nagoya, Japan, 25-28 October.

[7] Sayidmarie, K. H, and Fadhel, Y. A. (2012), Design Aspects of UWB Printed Elliptical Monopole Antenna with Impedance Matching, Loughborough Antennas \& Propagation Conference LAPC2012, UK, 12-13 November.

[8] Abbosh A. M. (2009), Miniaturized microstrip-fed 
tapered-slot antenna with ultrawideband

performance, IEEE Antennas and Wireless

Propagation Letters, vol. 8, 690-692.

[9] Ahirwar, S. D., and Sairam, C. (2010), Broadband Corrugated Square-Shaped Monopole Antenna. ISRN Communications and Networking, Vol 2011.

[10] Ray, K. P. (2008), Design aspects of printed monopole antennas for UWB applications. Hindawi Publishing Corporation, International Journal of Antennas and Propagation, 8 pages.

[11] Balanis C. A. (2005). Antenna theory analysis and design (3rd ed.). John Wiley \& Sons Inc.

[12] Matin M. A. (2011), Ultra wideband communications: novel trends-antennas and propagation, InTech, Croatia, pp. 177-183, July.

[13] Wadell, B. C. (1991). Transmission line design handbook. Norwood, MA: Artech House, ISBN: 0-89006-436-9.

[14] Wheeler, H. A. (1977), Transmission-line properties of a strip on a dielectric sheet on a plane, IEEE Tran. Microwave Theory Tech., Vol. MTT-25, No. 8, 631-647, Aug. 